\title{
Transbronchial needle aspirates: how many passes per target site?
}

\author{
A.H. Diacon*, M.M. Schuurmans*, J. Theron*, K. Brundyn\#, M. Louw*, \\ C.A. Wright ${ }^{\#}$ and C.T. Bolliger*
}

ABSTRACT: Transbronchial needle aspiration is a bronchoscopic sampling method for a variety of bronchial and pulmonary lesions. The present study investigated whether and how serial needle passes contribute to the yield of transbronchial needle aspiration at specific target sites.

A total of 1,562 needle passes, performed at 374 target sites in 245 patients with neoplastic disease $(82 \%)$, non-neoplastic disease $(15 \%)$ or undiagnosed lesions $(3 \%)$, were prospectively recorded and rated for anatomical location, size, bronchoscopic appearance and underlying disease.

Positive aspirates were obtained in $75 \%$ of patients and at $68 \%$ of target sites. A diagnosis was established with the first, second, third and fourth needle pass at $64,87,95$ and $98 \%$ of targets, respectively. The absolute yield varied strongly with target site features, but the stepwise increment to the maximum yield provided by serial passes was similar across target sites.

In conclusion, three transbronchial needle passes per site are appropriate when only a tissue diagnosis is sought and when alternative sites or sampling modalities are available. At least four or five passes should be carried out at lymph node stations critical for the staging of lung cancer.

KEYWORDS: Bronchoscopy, cytodiagnosis, fine-needle biopsy, lung neoplasms, neoplasm staging

$\mathbf{T}$ ransbronchial needle aspiration (TBNA) via flexible bronchoscopy (FB) is a wellestablished sampling method for a variety of bronchial, peribronchial or pulmonary lesions [1]. Its ability to establish diagnosis and staging in a single noninvasive intervention has made TBNA the key technique for the evaluation of patients with suspected lung cancer [2, 3]. Endobronchial ultrasound (EBUS) [4], computed tomography (CT) guidance [5] and rapid on-site evaluation (ROSE) improve TBNA yield [6, 7], but these methods require considerable resources and are not universally available. In the absence of EBUS and/or ROSE, it is common practice to perform several TBNA passes at a target site to minimise false-negative results. However, little is known about the value of serial aspirations. CHIN et al. [8] reported a plateau in yield after seven aspirates per patient and per nodal site, while other authors have reported the performance of two [9], two to three [10, 11], at least three [12], three to four [13] or three to five [14, 15] passes per site. It is well known that TBNA has a higher yield in neoplastic than in benign lesions, as well as in small cell lung cancer (SCLC) compared with nonsmall cell lung cancer (NSCLC) [3, 16]. Other predictors of positive aspirates are greater size of lymph nodes, infracarinal or right tracheobronchial position, visible mucosal abnormalities, such as a widened carina or erythema, and endobronchial mass lesions [1, 3, $9,10,17]$. It is unknown whether these parameters also predict a higher yield when fewer

The demonstration of positive N2 or N3 lymph nodes using TBNA avoids unnecessary surgical exploration, with its associated morbidity and cost $[3,18]$. Such procedures often require TBNA sampling of multiple sites, proceeding in a stepwise fashion from the highest-rated potentially involved nodal site to the primary tumour, followed by additional sampling modalities. Patient comfort and safety challenge the bronchoscopist to find an optimal compromise between TBNA yield and (possibly unnecessary) prolongation of the intervention. The present study investigated the yield of serial TBNA as a function of target site characteristics, with the aim of establishing a practical rule for sampling in routine practice.

\section{METHODS}

Patients, interventions and diagnoses

All patients undergoing FB with TBNA at the present authors' tertiary academic hospital (Tygerberg Academic Hospital, Cape Town, aspirates are performed at these sites.
AFFILIATIONS

Depts of *Internal Medicine, and

\#Anatomical Pathology, Tygerberg Academic Hospital, University of Stellenbosch, Cape Town, South Africa.

CORRESPONDENCE

A.H. Diacon

Dept of Internal Medicine

P0 Box 19063

7505 Tygerberg

South Africa

Fax: 27219317442

E-mail: ahd@sun.ac.za

Received:

April 232006

Accepted after revision:

September 142006

SUPPORT STATEMENT

A.H. Diacon was supported by a grant from the University of Stellenbosch (Cape Town, South Africa). None of the authors has a financial interest to declare. 
South Africa) from June 2001 to June 2004 were prospectively recorded. Four chest physicians experienced in TBNA performed all procedures, using standard fibreoptic or video bronchoscopes (models BF30 and BF1T160; Olympus, Hamburg, Germany) and standard TBNA for cytological specimens (Bard, Billerica, MA, USA) under topical anaesthesia (lidocaine $1 \%$ ) and conscious sedation (midazolam i.v. as needed). TBNA was always the leading sampling method and was supplemented at the discretion of the physician with appropriate additional modalities. For staging of suspected lung cancer, the potentially highest-rated nodal site was sampled first. If staging was not of concern, the most promising site for providing a diagnosis was sampled first. The final diagnosis was established using the results of the bronchoscopy or, in cases with negative $\mathrm{FB}$, with appropriate repeat or additional examinations. All patients signed informed consent. The study was approved by the institutional ethical review board.

\section{TBNA and target sites}

A target site for TBNA was defined as an area of interest on CT (anatomical lymph node station or other lesion within reach of TBNA) or a visible abnormality identified during FB. Target site features were prospectively recorded. At least five successive aspirates in close proximity were performed. Every aspirate was immediately expressed onto a numbered glass slide and reported separately. TBNA sampling ended when all target sites had been aspirated or when sufficient diagnostic material was found with ROSE. ROSE was performed by a cytopathologist as previously described [7]. The anatomical location of lymph node target sites was classified according to the American Thoracic Society system [18] into paratracheal sites above the tracheobronchial level (stations $2 \mathrm{R}$ and $2 \mathrm{~L}$ ), tracheobronchial sites (stations $4 \mathrm{R}, 4 \mathrm{~L}$ and 7) and bronchial sites (all sites below tracheobronchial). All sites were rated for normal or altered appearance (i.e. widened carina, mucosal infiltration, extrinsic compression). Compression of a lumen was rated for its degree as partial or complete (passable with bronchoscope or not) and for appearance (intrabronchial mass lesion opposed to submucosal or peribronchial disease). Post-bronchoscopy, the sites were further categorised for underlying disease (neoplastic or benign), type of lung cancer when applicable (SCLC or NSCLC), and short axis diameter in the case of tracheobronchial lymph nodes (assessed on contrasted spiral CT scan with 10-mm sections).

\section{Statistical analysis}

It was anticipated that sequential passes at a target site would result in stepwise yield increments to a plateau. Based on evidence in a published report [8], it was decided that five aspirates per site would provide sufficient data points to fit an exponential function with nonlinear regression (NewtonGauss). Every needle pass at a site was reported separately and entered into a database to provide yields after each sequential pass. Using these data, separate exponential functions were created to deduct the yields stratified for target site characteristics. Proportional data were analysed using a Chisquared test of contingency tables or Fisher's exact test on $2 \times 2$ contingency tables in the case of very small counts $(\leqslant 5)$. A p-value $<0.05$ was considered significant. Two-sided tests were used. Data are presented as mean $\pm \mathrm{SD}$ unless otherwise stated.

\section{RESULTS}

\section{Patients, diagnosis and interventions}

A total of 245 patients undergoing flexible bronchoscopy with TBNA were recorded (age range: $15-88 \mathrm{yrs}$; median $57 \mathrm{yrs}$; $66 \%$ male). The final diagnosis was neoplastic disease in 200 $(82 \%)$ and non-neoplastic disease in $36(15 \%)$. Nine $(3 \%)$ remained undiagnosed (table 1). Five of these patients died from clinically advanced malignancy before further investigations could be undertaken. One patient died undiagnosed from massive haemoptysis and three were lost to follow-up. TBNA was diagnostic in $75 \%$ of patients overall, in $84 \%$ with neoplastic disease and in $44 \%$ with benign lesions.

\section{Target sites}

In total, 374 target sites were sampled ( $1.53 \pm 0.6$ per patient) with 1,562 needle passes $(4.2 \pm 1.6$ per site; range $1-10)$. The site-specific yields are demonstrated in table 2. More than half of all target sites were at the tracheobronchial level (stations $4 R, 4 L, 7)$. Significantly higher yields were seen with increasing size of lymph nodes and at the tracheobronchial level in rightsided (station 4R) and infracarinal (station 7) compared to leftsided (station $4 \mathrm{~L}$ ) lymph nodes. Other statistically significant predictors of positive aspirates were the presence of a visible abnormality and neoplastic disease. Among abnormally appearing sites, endobronchial mass lesions were significantly more often positive than submucosal or peribronchial lesions. Of borderline significance was the better yield in SCLC compared to NSCLC. There was no significant difference between partial and complete endobronchial obstruction.

\section{Sequential yield of TBNA}

The cumulative yield obtained from the complete set of 1,562 needle aspirates at 374 sites is displayed in figure 1 . The first

\begin{tabular}{|c|c|c|c|}
\hline \multirow[t]{2}{*}{ TABLE 1} & \multicolumn{3}{|c|}{$\begin{array}{l}\text { Bronchoscopies, diagnoses and yield of } \\
\text { transbronchial needle aspiration (TBNA) }\end{array}$} \\
\hline & & $\begin{array}{l}\text { Underlying } \\
\text { disease }\end{array}$ & $\begin{array}{l}\text { Diagnostic } \\
\text { TBNA }^{\#}\end{array}$ \\
\hline All & & $245(100)$ & 75 \\
\hline \multicolumn{2}{|c|}{ Neoplastic disease } & $200(82)$ & 84 \\
\hline \multicolumn{2}{|c|}{ Nonsmall cell lung cancer } & $154(63)$ & 81 \\
\hline \multicolumn{2}{|c|}{ Adenocarcinoma } & $82(34)$ & 85 \\
\hline \multicolumn{2}{|c|}{ Squamous cell carcinoma } & $25(10)$ & 84 \\
\hline \multicolumn{2}{|c|}{ Undifferentiated carcinoma } & $47(19)$ & 72 \\
\hline \multicolumn{2}{|c|}{ Small cell lung cancer } & $39(16)$ & 95 \\
\hline \multicolumn{2}{|c|}{ Other neoplastic } & $7(3)$ & 86 \\
\hline \multicolumn{2}{|c|}{ Non-neoplastic disease } & $36(15)$ & 44 \\
\hline \multicolumn{2}{|c|}{ Sarcoidosis } & $10(4)$ & 60 \\
\hline \multicolumn{2}{|c|}{ Tuberculosis } & $14(6)$ & 71 \\
\hline \multicolumn{2}{|c|}{ Other infective lesions } & $5(2)$ & 0 \\
\hline \multicolumn{2}{|c|}{ Other benign lesions } & $7(3)$ & 0 \\
\hline \multicolumn{2}{|c|}{ Undiagnosed } & $9(3)$ & 0 \\
\hline
\end{tabular}




\section{TABLE 2 Target sites and yield of transbronchial needle aspiration}

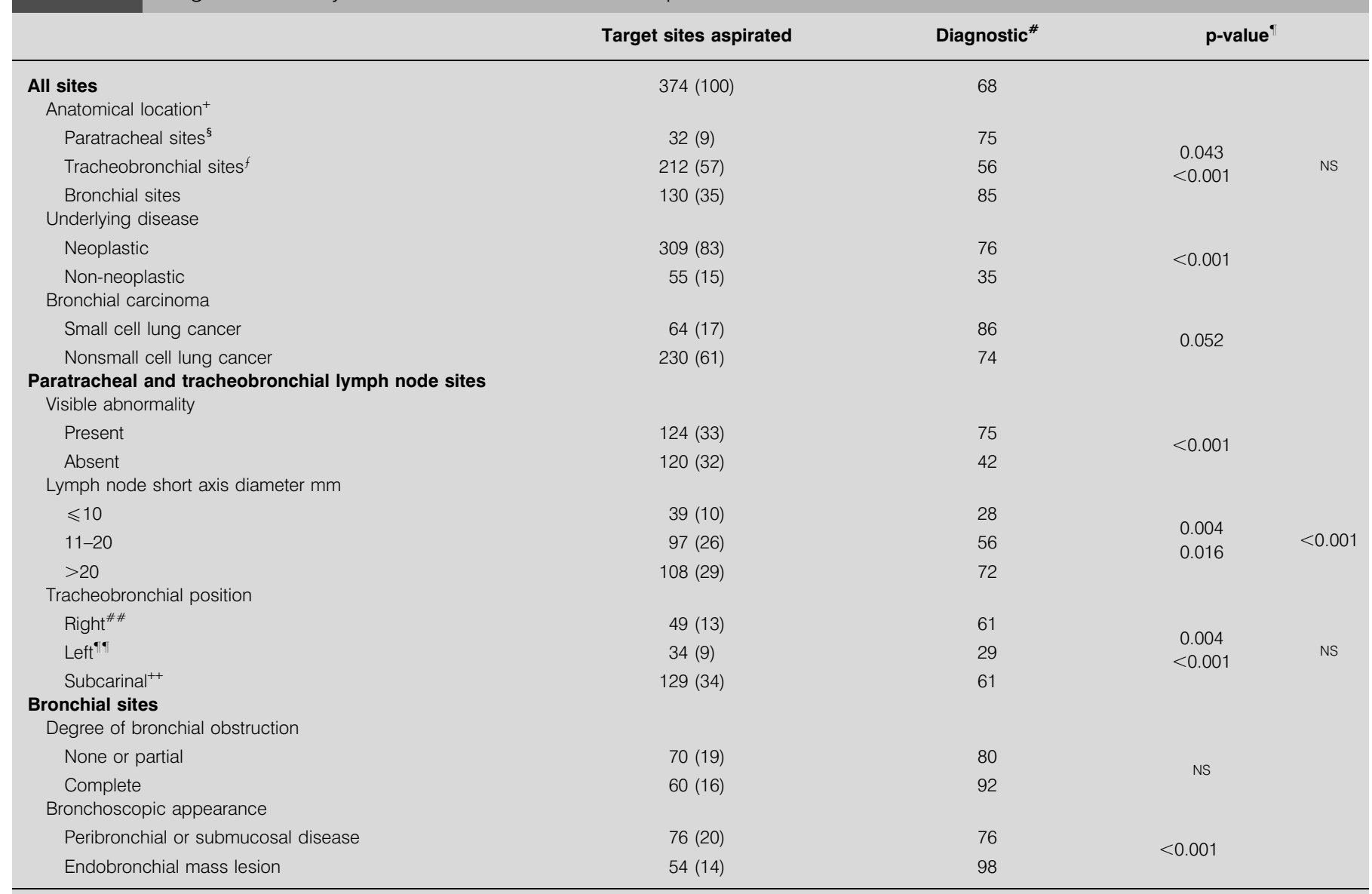

Data are presented as $\mathrm{n}(\%)$ and \%, unless otherwise stated. Ns: nonsignificant. ${ }^{\#}$ : at least one diagnostic transbronchial needle aspiration per target site. ${ }^{\top}$ : Where the Diagnostic column shows three values consecutively, the figures in left-hand part of the p-value column show a comparison of the first and second and then the second and third values; values in the right-hand p-value column show a comparison of the first and third values in the Diagnostic column. ${ }^{+}$: Iymph node station according to the

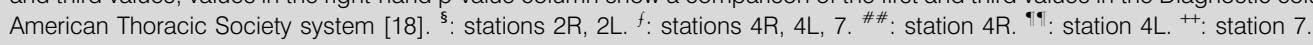

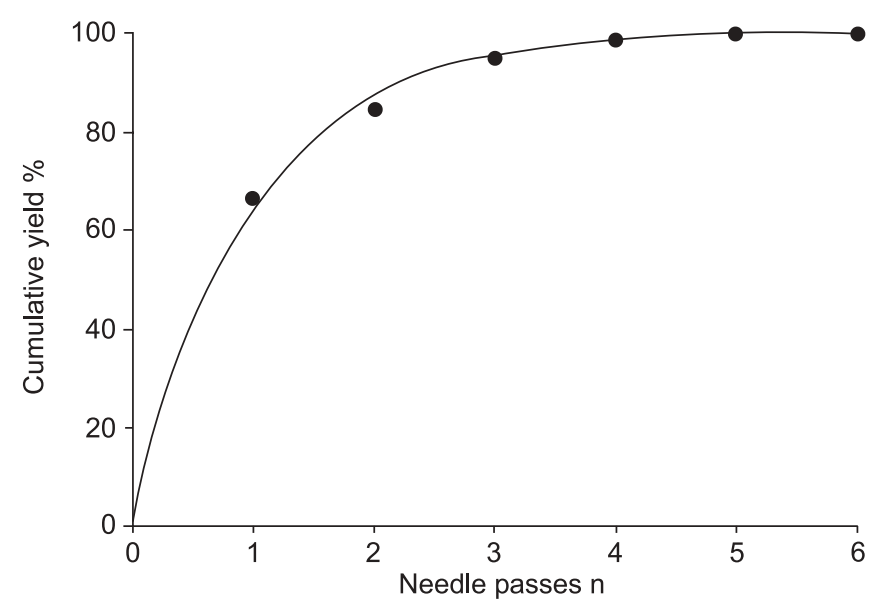

FIGURE 1. Incremental yield to plateau with sequential needle passes. The graph describes the yield to plateau in 1,562 transbronchial needle aspiration passes at 374 target sites.

- : measured yield after each sequential needle pass; — extrapolated yield from an exponential function, obtained by nonlinear regression. The function is "yield $=100-b 0 \times \mathrm{e}^{(\mathrm{b} 1 \times \text { needle passes)", }}$, where the coefficients b0 and b1 determine the shape of the curve. The correlation is excellent $\left(R^{2}=0.999\right)$. needle pass contributed the largest proportion to the total yield at all sites, and all following passes increased the yield by $\sim 50 \%$ of the increase brought about by the previous pass until a plateau was reached. As expected, this pattern could be described with a simple nonlinear function. The functions and graphs established for sites with specific features were very similar to figure 1 (data not shown; all correlation coefficients $\mathrm{R}^{2}>0.96$ ). Table 3 shows the proportional yields of the plateau yield after the first five sequential passes for each site. The highest first-pass contribution was achieved at sites with complete airway obstruction $(82.6 \%$ ) and in endobronchial mass lesions $(76.7 \%)$. At all sites, $\geqslant 88 \%$ of the plateau yield was reached with three passes and $\geqslant 94 \%$ with four needle passes.

\section{DISCUSSION}

The present study showed that the stepwise increase in TBNA yield with serial needle passes is similar across target sites of variable position, aspect, size and underlying disease. Although the rate of positive TBNA was significantly different across target sites, the first needle pass consistently contributed $\geqslant 50 \%$ towards the maximum yield, three passes provided 89 $99 \%$, and five passes yielded $\geqslant 98 \%$ at all sites. TBNA was 


\section{TABLE 3 Target sites and yield of sequential needle passes}

\begin{tabular}{|c|c|c|c|c|c|c|}
\hline & \multicolumn{5}{|c|}{ Yield after needle pass } & \multirow[t]{2}{*}{$\mathrm{Fit}^{\#} \mathbf{R}^{2}$} \\
\hline & 1 & 2 & 3 & 4 & 5 & \\
\hline All sites & 64.5 & 87.4 & 95.5 & 98.4 & 99.4 & 0.998 \\
\hline \multicolumn{7}{|l|}{ Anatomical location } \\
\hline Paratracheal sites ${ }^{+}$ & 59.6 & 83.8 & 93.5 & 97.4 & 99.0 & 0.996 \\
\hline \multicolumn{7}{|l|}{ Underlying disease } \\
\hline Neoplastic & 64.2 & 87.2 & 95.4 & 98.3 & 99.4 & 0.998 \\
\hline Non-neoplastic & 68 & 89.7 & 96.7 & 98.9 & 99.7 & 0.978 \\
\hline \multicolumn{7}{|l|}{ Bronchial carcinoma } \\
\hline Small cell lung cancer & 59.5 & 83.6 & 93.4 & 97.3 & 98.9 & 0.998 \\
\hline Nonsmall cell lung cancer & 65.8 & 88.3 & 96.0 & 98.6 & 99.5 & 0.998 \\
\hline Absent & 60.1 & 84.2 & 93.7 & 97.5 & 99.0 & 0.998 \\
\hline \multicolumn{7}{|l|}{ Lymph node short axis diameter $\mathrm{mm}$} \\
\hline$\leqslant 10$ & 64.8 & 87.8 & 95.8 & 98.5 & 99.5 & 0.968 \\
\hline $11-20$ & 59.2 & 83.2 & 93.1 & 97.2 & 98.8 & 0.995 \\
\hline$>20$ & 51.5 & 76.7 & 88.8 & 94.6 & 98.8 & 0.991 \\
\hline \multicolumn{7}{|l|}{ Tracheobronchial position } \\
\hline Right $^{f}$ & 54.5 & 79.4 & 90.7 & 95.8 & 98.1 & 0.995 \\
\hline Left $^{\# \#}$ & 60.3 & 84.3 & 93.8 & 97.5 & 99.0 & 0.992 \\
\hline Subcarinal" & 57.1 & 81.7 & 92.2 & 96.7 & 98.6 & 0.998 \\
\hline \multicolumn{7}{|l|}{ Bronchial sites } \\
\hline \multicolumn{7}{|l|}{ Degree of bronchial obstruction } \\
\hline None or partial & 67.4 & 89.3 & 96.5 & 98.9 & 99.6 & 0.997 \\
\hline
\end{tabular}

diagnostic in $75 \%$ of a large sample of patients representative for clinical practice.

The ideal number of TBNA passes per target site has not received much investigative attention in the past. One reason might be that a negative TBNA result can have a variety of causes, such as inadequate puncture technique or suboptimal sample preparation and analysis [17]. Secondly, TBNA has a sensitivity of only $76-80 \%$ in the best hands under study conditions $[10,19,20]$, which means that a negative result is of limited value even when established with a high number of aspirates. ROSE by a cytopathologist present in theatre will effectively optimise the number of aspirates in patients with positive TBNA but will contribute little when TBNA remains negative $[7,21]$. In contrast, EBUS improves TBNA sensitivity by assisting the positioning of the needle inside the target lesion [4]. However, the majority of chest physicians performing TBNA do not have easy access to EBUS or ROSE and will rely on their clinical judgement and personal experience to decide on the number of aspirates in specific bronchoscopic situations.
Tracheobronchial lymph-node sampling for staging of lung cancer is the best established and most widely used indication for TBNA. The current results in this subgroup of sites confirm previous reports that the yield of TBNA is strongly influenced by the size and location of the targeted lymph node, as well as by the presence of erythema and a widened carina $[3,16]$. Even though radiological size is a poor predictor for disease in the mediastinum [22], the current authors' yield in small nodes ( $<10 \mathrm{~mm}$ small axis diameter: $29 \%$ yield) is surprisingly high. HARROw et al. [10] reported a TBNA yield in tracheobronchial lymph nodes $<10 \mathrm{~mm}$ of $14 \%$ in a large sample of patients with lung cancer. The explanation for this discrepancy may be the inclusion of nodes measuring exactly $10 \mathrm{~mm}$ into that group in the present study. The current authors' yield in nodes measuring $<10 \mathrm{~mm}$ was only $16 \%$. For sites other than tracheobronchial, the present study confirms the prediction of positive aspirates by visible abnormalities such as a widened carina, submucosal infiltration, airway compression or endobronchial mass lesions $[9,16,17]$. 
The good overall yield of $75 \%$ in the present study encourages the use of TBNA regardless of the availability of EBUS support. While EBUS-guided TBNA is superior in lymph-node targets $<10 \mathrm{~mm}$ [23] or in peripheral lung lesions [24], most parabronchial lesions can be located using anatomical landmarks, such as the carina or lobar bifurcations [25, 26]. Moreover, positive ROSE-TBNA makes EBUS redundant and shortens the sampling process [7]. The preferred method for mediastinal staging will not only depend on the available expertise but also on the prevalence of mediastinal metastases. HOLTY et al. [20] have recently shown that TBNA has a higher sensitivity in more advanced mediastinal disease than in situations with small lymph nodes. This means that non-EBUS-TBNA is probably sufficient for the majority of patients for whom confirmation of inoperability is sought. Conversely, EBUSTBNA or even surgical staging is best used when a surgically operable stage is suspected and a high negative predictive value is important.

In conclusion, what can be recommended for general practice? Transbronchial needle aspiration is an elegant and effective technique that takes bronchoscopic sampling beyond visible abnormalities. Even though other sampling methods are often equally promising, frequent practice of transbronchial needle aspiration to hone technical skills is to be encouraged. In general, it seems reasonable to perform three serial transbronchial needle aspiration passes per site when the main objective is establishing a tissue diagnosis and when alternative target sites or other sampling modalities are equally promising. Four or even five transbronchial needle aspiration passes per site should be carried out if only a single site is available, if transbronchial needle aspiration is the only potentially diagnostic sampling method, and if the objective is staging of lung cancer at critical lymph node stations.

\section{REFERENCES}

1 Mazzone P, Jain P, Arroliga AC, Matthay RA. Bronchoscopy and needle biopsy techniques for diagnosis and staging of lung cancer. Clin Chest Med 2002; 23: 137-158.

2 Gasparini S, Silvestri GA. Usefulness of transbronchial needle aspiration in evaluating patients with lung cancer. Thorax 2005; 60: 890-891.

3 Minai OA, Dasgupta A, Mehta AC. Transbronchial needle aspiration of central and peripheral lesions. In: Bolliger CT, Mathur PN, eds. Interventional Bronchoscopy. Basel, Karger, 2000; pp. 66-79.

4 Herth FJ, Becker HD, Ernst A. Ultrasound-guided transbronchial needle aspiration: an experience in 242 patients. Chest 2003; 123: 604-607.

5 Geraghty PR, Kee ST, McFarlane G, Razavi MK, Sze DY, Dake MD. CT-guided transthoracic needle aspiration biopsy of pulmonary nodules: needle size and pneumothorax rate. Radiology 2003; 229: 475-481.

6 Davenport RD. Rapid on-site evaluation of transbronchial aspirates. Chest 1990; 98: 59-61.

7 Diacon AH, Schuurmans MM, Theron J, et al. Utility of rapid on-site evaluation of transbronchial needle aspirates. Respiration 2005; 72: 182-188.
8 Chin R, McCain TW, Lucia MA, et al. Transbronchial needle aspiration in diagnosing and staging lung cancer: how many aspirates are needed? Am J Respir Crit Care Med 2002; 166: 377-381.

9 Harrow E, Halber M, Hardy S, Halteman W. Bronchoscopic and roentgenographic correlates of a positive transbronchial needle aspiration in the staging of lung cancer. Chest 1991; 100: 1592-1596.

10 Harrow EM, Abi-Saleh W, Blum J, et al. The utility of transbronchial needle aspiration in the staging of bronchogenic carcinoma. Am J Respir Crit Care Med 2000; 161: 601-607.

11 Wang KP, Brower R, Haponik EF, Siegelman S. Flexible transbronchial needle aspiration for staging of bronchogenic carcinoma. Chest 1983; 84: 571-576.

12 Shure D. Transbronchial biopsy and needle aspiration. Chest 1989; 95: 1130-1138.

13 Schenk DA, Chambers SL, Derdak S, et al. Comparison of the Wang 19-gauge and 22-gauge needles in the mediastinal staging of lung cancer. Am Rev Respir Dis 1993; 147: 1251-1258.

14 Schenk DA, Bower JH, Bryan CL, et al. Transbronchial needle aspiration staging of bronchial carcinoma. Am Rev Respir Dis 1986; 134: 146-148.

15 Schenk DA, Bryan CL, Bower JH, Myers DL. Transbronchial needle aspiration in the diagosis of bronchogenic carcinoma. Chest 1987; 92: 83-85.

16 Utz JP, Patel AM, Edell ES. The role of transcarinal needle aspiration in the staging of bronchogenic carcinoma. Chest 1993; 104: 1012-1016.

17 Haponik EF, Cappellari JO, Chin R, et al. Education and experience improve transbronchial needle aspiration performance. Am J Respir Crit Care Med 1995; 151: 1998-2002.

18 Mountain CF, Dresler CM. Regional lymph node classification for lung cancer staging. Chest 1997; 111: 1718-1723.

19 Toloza EM, Harpole L, Detterbeck F, McCrory DC. Invasive staging of non-small cell lung cancer: a review of the current evidence. Chest 2003; 123: Suppl. 1, 157S-166S.

20 Holty JE, Kuschner WG, Gould MK. Accuracy of transbronchial needle aspiration for mediastinal staging of nonsmall cell lung cancer: a meta-analysis. Thorax 2005; 60: 949-955.

21 Baram D, Garcia RB, Richman PS. Impact of rapid on-site cytologic evaluation during transbronchial needle aspiration. Chest 2005; 128: 869-875.

22 Toloza EM, Harpole L, McCrory DC. Noninvasive staging of non-small cell lung cancer: a review of the current evidence. Chest 2003; 123: Suppl. 1, 137S-146S.

23 Herth FJ, Ernst A, Eberhardt R, Vilmann P, Dienemann H, Krasnik M. Endobronchial ultrasound-guided transbronchial needle aspiration of lymph nodes in the radiologically normal mediastinum. Eur Respir J 2006; 28: 910-914.

24 Paone G, Nicastri E, Lucantoni G, et al. Endobronchial ultrasound-driven biopsy in the diagnosis of peripheral lung lesions. Chest 2005; 128: 3551-3557.

25 Herth F, Becker HD, Ernst A. Conventional vs endobronchial ultrasound-guided transbronchial needle aspiration: a randomized trial. Chest 2004; 125: 322-325.

26 Trisolini R, Agli LL, Patelli M. Conventional vs endobronchial ultrasound-guided transbronchial needle aspiration of the mediastinum. Chest 2004; 126: 1005-1006. 